\title{
TCCS
}

\section{PROJETO FLORESCER - HABITAÇÃO DE INTERESSE SOCIAL INCORPORANDO MATERIAIS LOCAIS E RESÍDUOS SÓLIDOS}

\author{
Lluvia Deluz Perdomo, Arquiteta e Urbanista; \\ Orientador - Lisiane llha Librelotto, Dr. Eng. (UFSC)
}

\section{INTRODUÇÃO}

A ideia principal deste Trabalho de Conclusão de Curso (TCC), em Arquitetura e Urbanismo, na UFSC, foi aliar a necessidade de redução de custos e de impactos ambientais, com o trabalho em comunidade, onde a mão de obra própria representa um duplo benefício (reduz o custo ao mesmo tempo em que assegura o direito à moradia). Assim, desenvolveu-se o projeto de uma Habitação de Interesse Social, para construção em regime de mutirão, utilizando materiais do próprio local, com baixo custo, pouca energia incorporada e incorporando resíduos.

\section{REFERENCIAL TEÓRICO}

De acordo com a Fundação João Pinheiro (2009), o conceito de déficit habitacional está ligado às deficiências do estoque de moradias. Inclui aquelas moradias sem condições de habitabilidade, devido à precariedade das construções ou em virtude de desgaste em sua estrutura física. No déficit habitacional incluiu-se, ainda, a necessidade de incremento do estoque, devido à coabitação familiar forçada (famílias que pretendem constituir um domicílio unifamiliar), aos moradores de baixa renda que não possuem condições de arcar com o pagamento de um aluguel e aos que vivem em imóveis alugados com grande densidade de pessoas. Inclui-se ainda nesta rubrica a moradia em imóveis não residenciais.

Para Addis (2010) o reaproveitamento de resíduos como material de construção pode ser considerado uma boa alternativa. Devido ao crescimento da população e a manifestação de uma cultura de consumo, onde o que não serve é jogado fora e trocado rapidamente, a geração de resíduos individuais tem aumentado de forma exponencial, gerando graves impactos ambientais, sociais e econômicos nas cidades.

Soma-se as isto a necessidade de se avaliar o ciclo de vida dos materiais e da edificação. (ABNT, NBR14040). Assim, os materiais utilizados na propostas devem apresentar, apenas sob o aspectos de energia incorporada considerada nesta proposta, baixo consumo.

Para a definição das técnicas construtivas e referencias para projeto utilizou-se os trabalhos de Promt (2012), Armando (2014), a experiência do Cajueiro Seco (SOUZA, 2008), a Soe Ker Tie House (TYIN ARCHITECTS, 2014), Lotufo (2015) e análise de imóveis ofertados disponibilizados pela Prefeitura Municipal de Florianópolis (PMF, 2015).

\section{DESENVOLVIMENTO}

O local selecionado para implementação é o assentamento da Comuna Amarildo. Em dezembro de 2013 a Ocupação Amarildo surgiu às margens da SC-401, em Florianópolis. A intenção dos integrantes era tomar o local para produzir alimentos e tirar famílias do aluguel. Falava-se em fazer reforma agrária dentro da cidade e frear a especulação imobiliária na Ilha. Deixaram o terreno e tentaram mais duas ocupações em Maciambú, na Palhoça e no Rio Vermelho, em Florianópolis.

Chegou a ser cogitado um terreno em Canoinhas para o assentamento, mas foi realizado em Àguas Mornas. Atualmente residem no assentamento 11 famílias entre homens, mulheres, idosos e crianças de todas as faixas etárias.

A renda principal no assentamento neste período inicial ainda é oriundo de trabalho assalariado externo a 
propriedade.

Após a implementação de projetos de estufas e melhores condções de plantio, a produção de hortaliças cresceu e o objetivo é que passe a ser o principal meio de subsistência das famílias.

As casas atuais são todas construídas em lona e madeira, sendo realizado mutirões entre as famílias para otimizar a construção das residências e promover o espírito do trabalho coletivo.

Optou-se por abordar neste trabalho 5 familias, identificadas na figura 1.

Figura 1: Habitações existentes das 5 famílias selecionadas.
Figura 2: Painel em bambu, vedado com esterilhas para taipa, montado apenas com encaixes.

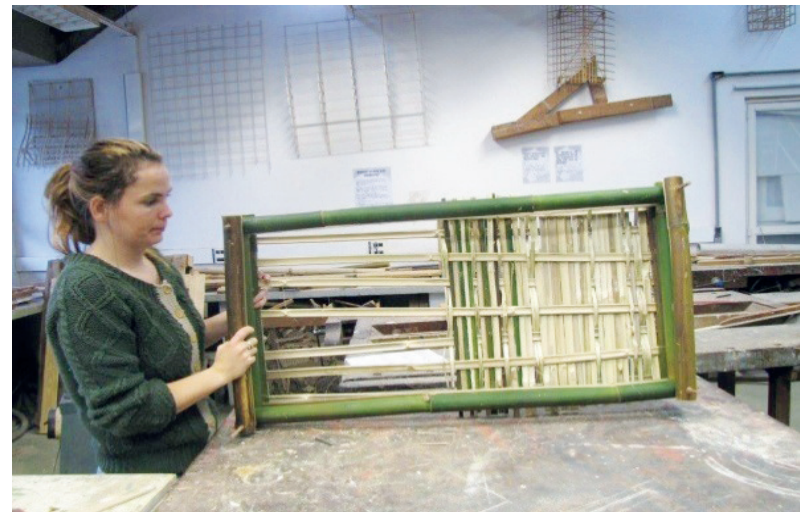

Fonte: Perdomo (2015)

Figura 3: Blocos de adobe utilizando garrafas PET nos furos.

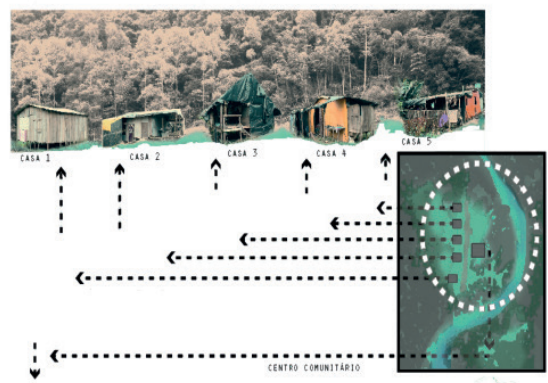

Fonte: Perdomo (2015)

As construções existentes são constituídas de restos de materiais, principalmente madeiras (compensados e tábuas), lona e telhas onduladas, sem qualquer cuidado quanto à técnica construtiva.

O local dispunha de terra, madeira de reflorestamento (Eucalipto), Bambu, Pneus, Pallets, Serragem e Fibras naturais passíveis de serem utilizados como materiais de construção.

A partir da terra coletada no local, foram feitos testes (confecção de tarugo) conforme sugerido por Minke (data). Assim para uso da terra percebeu-se a necessidade de estabilização com fibras vegetais e adição de areia.

Foram propostas duas alternativas para composição dos elementos de vedação: blocos em adobe utilizando fibras do local e incorporação de garrafas PET e painéis de bambu para compor taipa, preenchidos com garrafas PET.

Foram confeccionados dois modelos experimentais das alternativas construtivas, conforme as figura 2 e 3 .

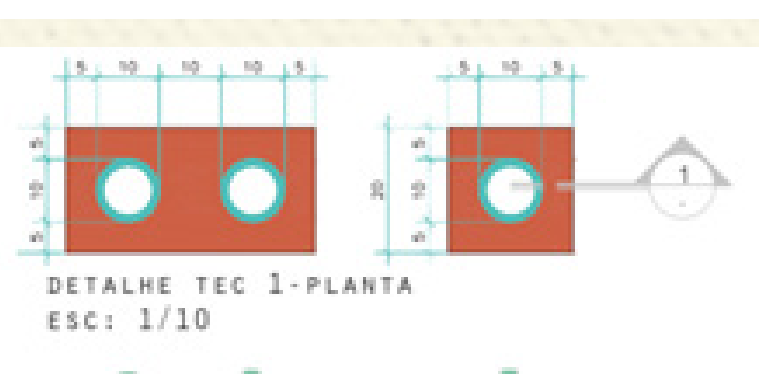

Fonte: Perdomo (2015)

A proposta arquitetônica partiu da colmeia (figura 4).

Figura 4: Projeto Florescer (evolução e ampliação).

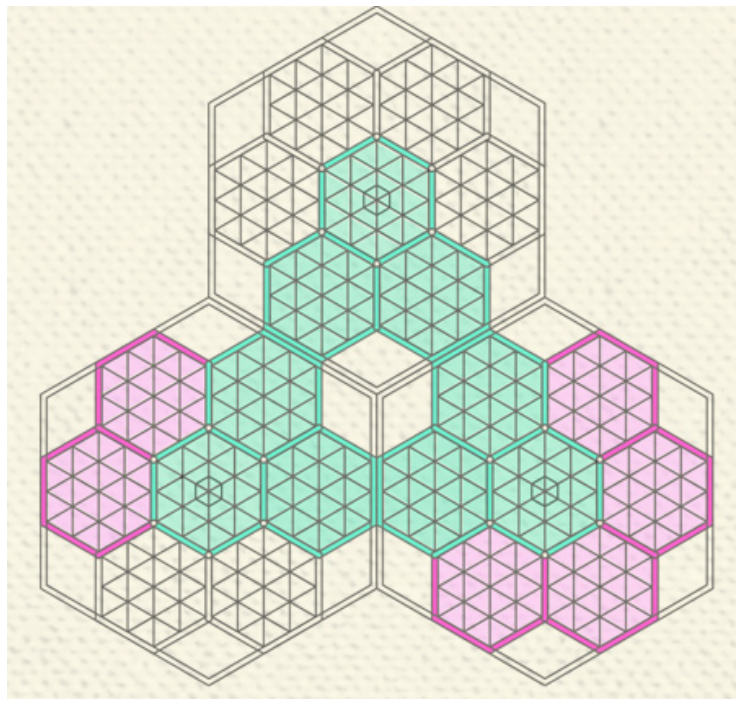

Fonte: Perdomo (2015) 
As figuras 5, 6 e 7 mostram as representações da proposta.

Figura 5: Esquema dos fluxos térmicos, ventilação e coleta de resíduos.

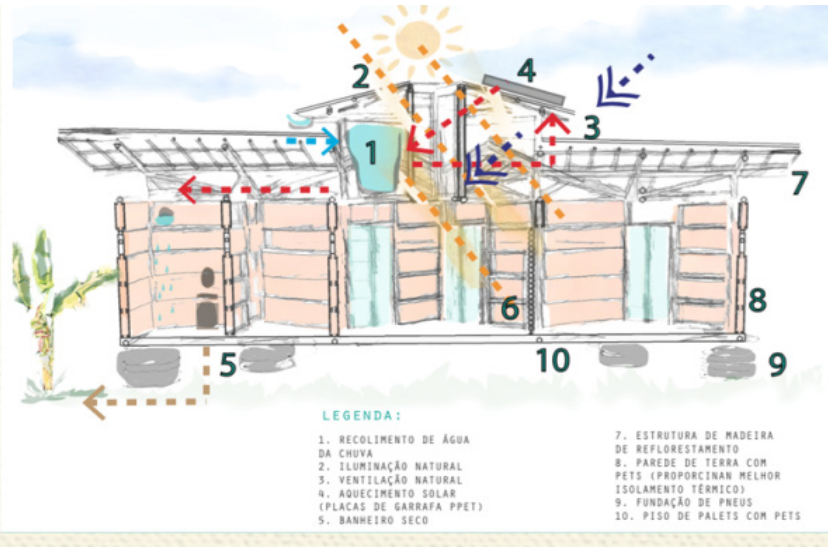

Fonte: Perdomo (2015)

Figura 6: Corte transversal com esquema da estrutura e fundação.

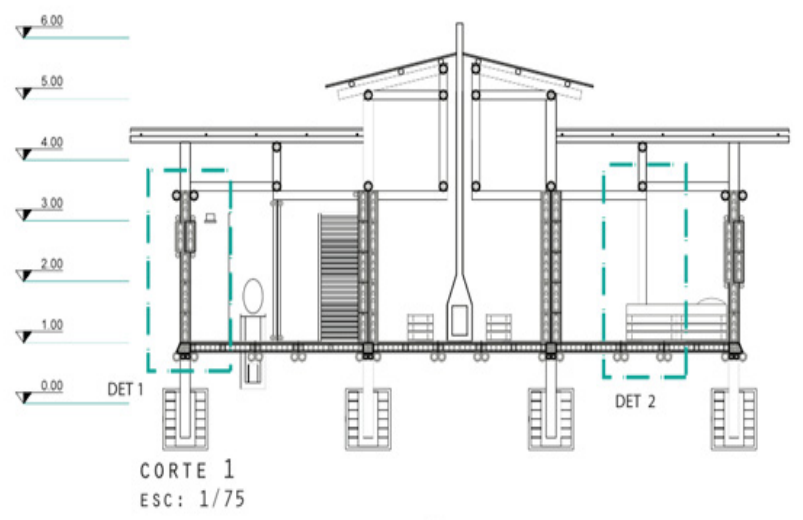

Fonte: Perdomo (2015)

Figura 7: planta baixa do embrião e ampliação.

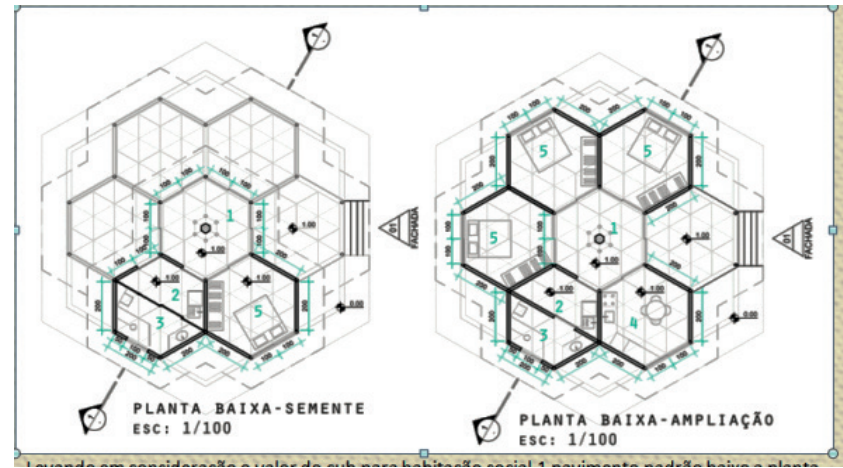

Fonte: Perdomo (2015)

\section{CONSIDERAÇÕES FINAIS}

Após uma compreensão do significado de habitação para o ser humano, a incorporação de resíduos, o uso de materiais locais com baixa energia incorporada, percebe-se que é possível pensar em uma arquitetura aliada à sustentabilidade.

Este projeto é uma pequena parte da imensidão de possibilidades construtivas com resíduos aliados a outras técnicas, como a construção com terra e com bambu. Foi um processo de compreensão do ser humano e das condições precárias em que ele pode viver, mas, que apesar de tudo, ainda é capaz de lutar por uma vida mais digna.

Devido à precariedade da situação atual da Comuna Amarildo, houve a necessidade de repensar as técnicas de construção envolvidas de forma a propiciar financiamentos ou mesmo, questões de manutebilidade da edificação. A forma proposta (hexágono) permite a expansão para adaptação ao ciclo familiar. Por fim conclui-se que é possível conciliar as questões econômicas às socioambientais, para todas as pessoas envolvidas no projeto.

\section{REFERÊNCIAS}

ABNT NBR ISO 14040:2009. Versão corrigida em 2014. Gestão ambiental - Avaliação do ciclo de vida - Princípios e estrutura.

ADDIS, Bill. Reuso de materiais e elementos de construção. São Paulo: Oficina de Textos, 2010.

ARMANDO, Clarissa. Construção com Terra Ensacada- Recomendações e Boas Práticas. Dissertação de Mestrado. PósARQ/UFSC. 2015.

Lotufo, Vitor. Livros e experiências do Arquiteto. Disponível em: < www.vitorlotufo.com.br>. Acesso: 2015.

MINKE, G. Manual de construcción para viviendas antisísmicas de tierra. Forschungslabor für Experimentelles Bauen. Universidad de Kassel, 2001.

Fundação João Pinheiro. Disponível em: < http://www.fjp. mg.gov.br> . Acesso: 2015.

PMF. Habitações. Disponível em:< www.pmf.com.br>. Acesso: 2015.

PERDOMO, Lluvia. Projeto Florescer - Habitação de Interesse Social Incorporando Materiais Locais e Resíduos Sólidos. TCC. Arquitetura e Urbanismos. UFSC. Florianópolis, 2015. PROMPT, Cecília. Arquitetura de Terra em Unidades Agrícolas Familiares: Estudo de Caso no Oeste Catarinense. PóSARQ. UFSC, 2012.

SOUZA, D. B. I. de. Reconstruindo cajueiro seco: Arquitetura, política social e cultura popular em Pernambuco (196064). Dissertação FAU, USP (2008). 